\title{
Lineage-dependent role of miR-410-3p as oncomiR in gonadotroph and corticotroph pituitary adenomas or tumor suppressor miR in somatotroph adenomas via MAPK, PTEN/AKT, and STAT3 signaling pathways
}

\author{
Tomasz M. Grzywa $\mathbb{1}^{1,2} \cdot$ Klaudia Klicka $\mathbb{C}^{1,2} \cdot$ Beata Rak $\mathbb{1}^{1,2,3,4} \cdot$ Dawid Mehlich ${ }^{1,2,5} \cdot$ Filip Garbicz $\mathbb{D}^{1,2,3,6}$. \\ Grzegorz Zieliński $^{7} \cdot$ Maria Maksymowicz $^{8} \cdot$ Emir Sajjad $^{2,7} \cdot$ Paweł K. Włodarski ${ }^{1,2}$
}

Received: 22 December 2018 / Accepted: 16 April 2019 / Published online: 4 June 2019

(c) The Author(s) 2019

\begin{abstract}
Purpose miR-410-3p plays opposite roles in different cancers and may act as an oncomiR or tumor suppressor miR. The purpose of this study was to assess the role of miR-410-3p in somatotroph, gonadotroph, and corticotroph pituitary adenomas. Methods Tissue samples were obtained from 75 patients with pituitary adenoma. miR-410-3p expression was assessed using qRT-PCR performed on RNA isolated from fresh frozen samples. In vitro experiments were performed on cell lines derived from somatotroph (GH3), gonadotroph (RC-4B/C), and corticotroph (AtT-20) pituitary tumors. Cells were transfected with synthetic mimic of miR-410-3p or non-targeting scrambled-miR control. Subsequently, proliferation assays and transwell invasion assays were performed. The expression of cyclin D1, E1, and B1 in cells after transfection was determined using qRT-PCR. The activation of MAPK, PTEN/AKT and STAT3 signaling pathways were assessed using western blot.

Results We have found that the level of expression of miR-410-3p differs in particular types of pituitary adenomas. miR410-3p significantly upregulates proliferation and invasiveness of RC-4B/C and AtT-20 cells, while inhibiting GH3 cells. We observed that the levels of cyclin B1 upon transfection with miR-410-3p mimic were increased in RC-4B/C and AtT-20, yet decreased in GH3 cells. We have shown that miR-410-3p promoted the activation of MAPK, PTEN/AKT, and STAT3 signaling pathways in RC-4B/C and AtT-20 cells, but suppressed their activity in GH3 cells.

Conclusions miR-410-3p acts as an oncomiR in gonadotroph and corticotroph adenoma cells, while as a tumor suppressor miR in somatotroph adenoma cells.
\end{abstract}

Keywords miR-410-3p $\cdot$ Pituitary adenoma $\cdot$ Proliferation $\cdot$ Invasiveness $\cdot$ MicroRNA $\cdot$ PTEN

\section{Introduction}

Pituitary adenomas are benign tumors of the sellar region which arise from the anterior lobe of the pituitary gland. They represent the third most frequent intracranial tumors [1].

These authors contributed equally: Tomasz M. Grzywa, Klaudia Klicka

Supplementary information The online version of this article (https:// doi.org/10.1007/s12020-019-01960-7) contains supplementary material, which is available to authorized users.

\section{Beata Rak}

beata.rak@wum.edu.pl

Extended author information available on the last page of the article
miRs (microRNAs, miRNAs) are single-stranded, stable, non-coding small RNA molecules, consisting of about 21-24 nucleotides. They play an important role in posttranscriptional regulation of gene expression by suppressing mRNA translation and also reducing mRNA stability. Thus, they control the pathogenesis of the majority of diseases and multiple types of human cancer [2]. miRs regulate all hallmarks of cancer, including the proliferation and invasiveness [3-5]. According to the predominant function of given $\mathrm{miR}$ in a cancer cell, we can distinguish oncomiRs and tumor suppressor miRs [6]. Recent studies show a significant impact of miRs on the pathogenesis of pituitary adenomas [7-14].

A number of articles, including our previous studies $[15,16]$ indicate miR-410-3p may act as a tumor suppressor $\mathrm{miR}$ in pancreatic, breast, bone, endometrial, and gastric cancers. However, its function seems to be reversed in some 
other neoplasms, where it functions as an oncomiR (non-small cell lung, liver, and colorectal cancers). It promotes or inhibits cell proliferation, invasion, migration, and apoptosis [17].

Due to the diverse functions of miR-410-3p in different types of cancer, we decided to examine the role of miR-410$3 \mathrm{p}$ in somatotroph, gonadotroph, and corticotroph pituitary adenoma cells.

\section{Materials and methods}

\section{Patient samples}

A retrospective group of 75 patients diagnosed with pituitary adenoma consisting of 34 gonadotroph, 30 somatotroph, 5 corticotroph, 3 plurihormonal, and 3 null cell tumors were enrolled for this study. Tumor samples were retrieved from patients undergoing planned transsphenoidal surgery at the Department of Neurosurgery, Military Institute of Medicine, Warsaw during the years 2014-2016. All tumors were examined by a pathologist. A local ethics committee approved all aspects of this study in accordance with the Helsinki Declaration.

\section{RNA isolation from tissue, reverse transcription, and quantitative polymerase chain reaction (qPCR)}

Total RNA was isolated from 75 fresh frozen tissues: 30 somatotroph, 3 plurihormonal, 34 gonadotroph, 5 corticotroph, and 3 null cell pituitary adenomas using AllPrep DNA/RNA Kit (Qiagen). MicroRNA expression levels were determined using TaqMan Advanced miRNA Assays, hsamiR-410-3p (assay ID: 001274), hsa-miR-484-5p (assay ID: 478308), and hsa-miR-24 (assay ID: 477992) (Thermo Fisher Scientific) according to the manufacturer's protocol. RNA was reverse transcribed using TaqMan Advanced miRNA cDNA Synthesis Kit (Thermo Fisher Scientific). All qPCRs were performed in MicroAmp Fast Optical 96 Well Reaction Plates (Thermo Fisher Scientific) using Applied Biosystems 7500 Fast Real-Time PCR System with 7500 Software V2.0.6 (Thermo Fisher Scientific). Samples were assayed in triplicates. The obtained $\mathrm{Ct}$ values for miR-410$3 p$ as well as mean miR-24 and miR-484 as an endogenous control were used to calculate relative expression using the $2^{-\Delta \mathrm{Ct}}$ method as described previously [18]. We used the mean $\mathrm{Ct}$ values for miR-24 and miR-484 as reference based on our analyses using NormFinder Software [19].

\section{Cell culture}

Pituitary adenoma cell lines: rat plurihormonal with predominantly $\mathrm{FSH} \beta+$ and $\mathrm{LH} \beta+$ cells [20] RC-4B/C (ATCC $^{\circledR}$ CRL-1903 ${ }^{\mathrm{TM}}$ ), therefore referred to as a gonadotroph cell line, rat somatotroph GH3 (ATCC ${ }^{\circledR} \mathrm{CCL}-$ $82.1^{\mathrm{TM}}$ ), and murine corticotroph AtT-20 (ATCC ${ }^{\circledR} \mathrm{CCL}-$ $89^{\mathrm{TM}}$ ) were obtained from the American Type Culture Collection. Cells were maintained according to the manufacturer's instructions. All cell culture media and reagents were purchased from Gibco BRL (Gran Island, NY, USA).

\section{Transfection}

All transfections were performed using jetPRIME (Polyplus) according to the manufacturer's protocol. miR-410-3p mimic (assay ID: MC11119) and miR-scrambled (miR-scr, miRNA Mimic Negative Control) were obtained from Invitrogen ${ }^{\mathrm{TM}}$ mirVana $^{\mathrm{TM}}$ (Thermo Fisher Scientific). miRs were used at a final concentration of $50 \mathrm{nM}$. The efficiency of transfection was confirmed using qRT-PCR (Supplementary Fig. 1)

\section{Proliferation and colony formation assay}

For proliferation assay, $5 \times 10^{4}$ cells/well were seeded in 12-well plates $24 \mathrm{~h}$ after transfection and were incubated for $72 \mathrm{~h}$. Then, cells were fixed with $4 \%$ PFA and stained with $0.1 \%$ crystal violet. For colony formation assay, $2.5 \times 10^{3}$ cells/well were seeded in 6-well plates $24 \mathrm{~h}$ after transfection. Cells were incubated 14 days with medium change every 3 days. Then, they were fixed and stained. For both proliferation and colony formation assays, AtT-20 cells were suspended in PBS and photographed. The photos were analyzed using ImageJ (National Institutes of Health, Bethesda MD, USA) and ColonyArea plugin [21].

\section{MTT}

CellTiter $96^{\circledR}$ Aqueous One Solution Cell Proliferation Assay (Promega) was performed according to the manufacturer's protocol. $5 \times 10^{3}$ cells/well in 96-well plates were seeded $24 \mathrm{~h}$ after transfection and incubated for 48, 96, 144, 192, and $240 \mathrm{~h}$. Absorbance at $570 \mathrm{~nm}$ was measured using FLUOstar OPTIMA (BMG Labtech).

\section{Invasion assay}

Cells were transfected as described above. VWR ${ }^{\circledR}$ Tissue Culture Plate Inserts, PET Membrane $8.0 \mu \mathrm{m}$ (VWR) were coated with $100 \mu \mathrm{l}$ of Matrigel (Corning) in serum-free medium in final concentration $250 \mu \mathrm{l} / \mathrm{ml}$. $1.5 \times 10^{5}$ cells in $250 \mu \mathrm{l}$ half-supplemented medium (7.5\% FBS for RC-4B/C, $1.25 \%$ FBS and $7.5 \%$ horse serum for GH3 and AtT-20) were seeded $24 \mathrm{~h}$ after transfection in inserts placed in 24-well plates filled with full medium (15\% FBS or $2.5 \%$ FBS and $15 \%$ horse serum, respectively). After overnight incubation, $250 \mu \mathrm{l}$ serum-free medium was added to inserts. After $24 \mathrm{~h}$, the non-invading cells were removed from the 

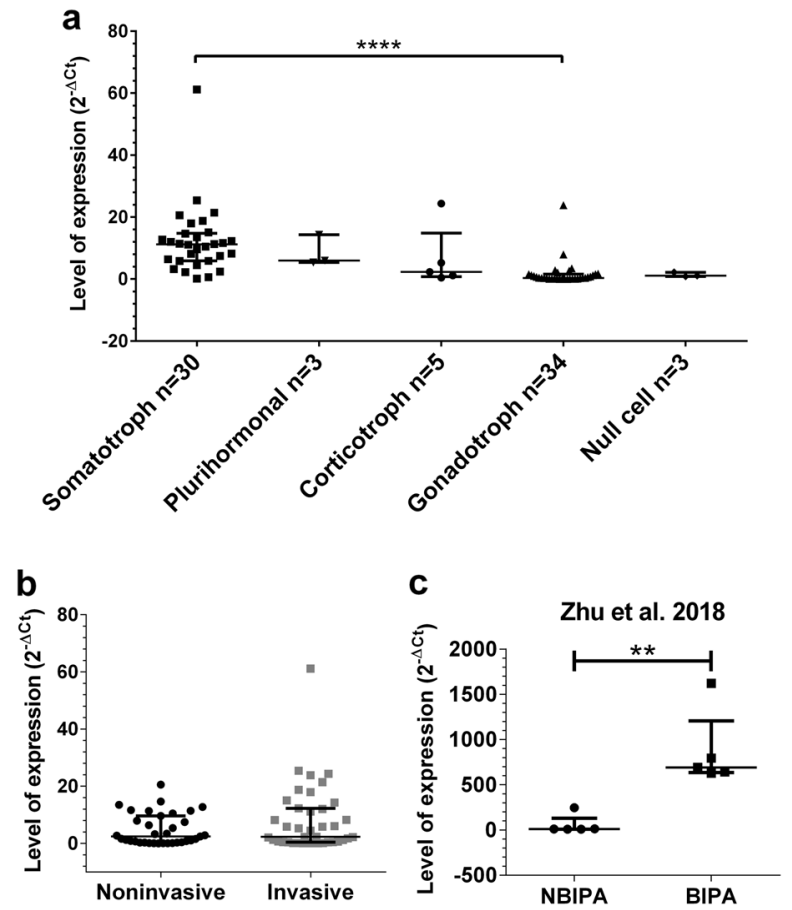

Fig. 1 a The comparison of the expression of miR-410-3p in different subtypes of pituitary adenomas ( $p<0.0001$, Kruskal-Wallis test). Significantly higher expression in somatotroph tumors compared to gonadotroph $(p<0.0001$, Dunn's multiple comparisons test). Median with interquartile range. $\mathbf{b}$ The comparison of the expression of miR$410-3 p$ in noninvasive (Knosp grade 0 and 1) and invasive (Knosp grade 2, 3, and 4) pituitary adenomas ( $p>0.05$, Mann-Whitney test). Median with interquartile range. $\mathbf{c}$ Overexpression of miR-410-3p in bone-invasive pituitary adenomas (BIPA) compared to nonboneinvasive pituitary adenomas (NBIPA) $(p=0.0031$, Mann-Whitney test, data obtained by Zhu et al. [22]). Median with interquartile range. $* * p<0.01$

upper surface of the membrane. The invading cells on the lower surface of the membrane were fixed with methanol and stained with $0.1 \%$ crystal violet in $20 \%$ ethanol. Five photos of each insert were taken with Nikon Eclipse TE2000-U. The photos were analyzed using ImageJ (National Institutes of Health, Bethesda MD, USA).

\section{RNA isolation from cells, reverse transcription, and qRT-PCR}

Total RNA was isolated from cells $24 \mathrm{~h}$ after transfection using AllPrep DNA/RNA (Qiagen). Up to $5 \mu \mathrm{g}$ of RNA was subjected to reverse transcription using GoScript Reverse Transcription Kit (Promega). Real-time qPCR was performed using Power SYBR ${ }^{\mathrm{TM}}$ Green PCR Master Mix (Thermo Fisher Scientific). The sequences of primers are shown in Supplementary Table 1 . The mean $\mathrm{Ct}$ values of the target gene and GAPDH as an endogenous control in miR-410-3ptransfected cells and miR-scrambled as a control were used to calculate relative expression using the $2^{-\Delta \Delta \mathrm{Ct}}$ method.

\section{Western blot}

The proteins were extracted from cells $48 \mathrm{~h}$ after transfection using Cell Lysis Buffer (cat. no. 9803; Cell Signaling Technology, Inc.), subsequently resolved on $12 \%$ polyacrylamide gels, and transferred to PVDF membranes (Millipore, Temecula, CA, USA). Membranes were blocked in $5 \%$ bovine serum albumin (Sigma) in TBST buffer and incubated overnight at $4{ }^{\circ} \mathrm{C}$ with primary antibodies and subsequently incubated with appropriate HRP-labeled secondary antibodies (Santa Cruz Biotechnology) for $1 \mathrm{~h}$ at room temperature. The list of primary antibodies is shown in Supplementary Table 2. The blots were visualized with Western Lighting Ultra ECL (PerkinElmer, Surrey, UK) by ChemiDoc Imaging System (Biorad, Hercules, CA, USA). The level of expression was assessed using densitometric analysis in ImageJ (National Institutes of Health, Bethesda MD, USA). For each western blot $\beta$-actin was used as a loading control. Relative expression of proteins in miR-410$3 \mathrm{p}$-transfected cells was calculated in relation to miR-scrtransfected cells. Relative levels of phosphorylated protein forms were additionally calculated in relation to total proteins followed by a normalization to miR-scrtransfected cells.

\section{Statistical analyses}

All experiments were performed in triplicates. Appropriate statistical test, Mann-Whitney test, unpaired $t$-test, paired $t$-test or Kruskal-Wallis test with Dunn's multiple comparisons test, were applied to assess mean differences between groups. All data were tested using Shapiro-Wilk normality test. All statistical tests were performed using GraphPad Prism 6 (GraphPad Sofware Inc.). All values are represented as mean \pm SD or median and interquartile ranges for nonparametric distributions. A $p$-value of $<0.05$ was considered statistically significant.

\section{Results}

\section{miR-410-3p is upregulated in invasive tumors compared to noninvasive}

We analyzed the level of expression of miR-410-3p in 34 gonadotrophs, 30 somatotrophs, 5 corticotrophs, 3 plurihormonal, and 3 null cell pituitary adenomas (Fig. 1a). The expression level was highest in somatotroph pituitary adenomas (mean $2^{-\Delta \mathrm{Ct}}=12.19$, median $=11.21$ ) while lowest in null cell adenomas (mean $=1.40$, median $=1.14$ ) and gonadotroph adenomas $($ mean $=1.66$, median $=0.3592)$. The mean expression of miR-410-3p in corticotroph tumors was 6.72 (median $=2.29)$ while in plurihormonal it was 
8.54 (median $=5.99)$. We did not observe a statistically significant difference between the expression of miR-410$3 p$ in invasive tumors (Knosp grade 2, 3, and 4, mean = $8.15 \pm 11.76$, median $=2.29$ ) compared to noninvasive $($ Knosp grade 0 and 1 , mean $=4.76 \pm 5.48$, median $=2.40)$, largely due to a considerable heterogeneity in miR-410-3p expression that we observed (Fig. 1b, $p>0.05$ ). However, based on analysis of an expression dataset published by Zhu et al. [22], miR-410-3p was significantly overexpressed in bone-invasive pituitary adenomas (BIPA) compared to nonbone-invasive pituitary adenomas (NBIPA) (fold change 15.13, $p=0.0031)$ Fig. 1c.

\section{miR-410-3p upregulates proliferation and invasion in RC-4B/C and AtT-20 cells, but downregulates in GH3 cells}

To identify the effect of miR-410-3p on cells proliferation in pituitary adenoma cells, we performed MTT and proliferation assays using model cell lines. miR-410-3p promoted proliferation in $\mathrm{RC}-4 \mathrm{~B} / \mathrm{C}$ and $\mathrm{AtT}-20$ cells, while it reduced the proliferative potential of $\mathrm{GH} 3$ cells. Based on proliferation assay, miR-410-3p increased $\mathrm{RC}-4 \mathrm{~B} / \mathrm{C}$ cells proliferation $(1.25, p=0.0008)$ and AtT-20 $(1.18, p=0.0002)$, while decreased GH3 cells proliferation $(0.78, \quad(p=0.0008)$ (Fig. 2a). We found that relative colony formation was higher in miR-410-3p-transfected RC-4B/C cells $(1.23, p<0.0001)$ and AtT-20 cells $(1.10, p=0.0003)$ but lower in miR-410$3 p$-transfected GH3 cells $(0.80, p<0.0001)$, Fig. 2 b.

In order to dissect the role of miR-410-3p in the regulation of pituitary adenomas invasiveness, we performed transwell invasion assays with membranes coated with Matrigel. The results are shown in Fig. 2c. We found that miR-410-3p downregulated invasiveness in GH3 cells with the relative invasion of 0.78 compared to miR-scr $(p=$ 0.0094). Conversely, miR-410-3p substantially upregulated cell invasiveness in $\mathrm{RC}-4 \mathrm{~B} / \mathrm{C}$ cells with the relative invasion $1.72(p<0.0001)$ as well as in AtT-20 cells with the relative invasion $1.84(p=0.0128)$.

Representative photos of proliferation assay, colony formation assay, and invasion assay are shown in Fig. 2d. Furthermore, MTT assay showed that the differences in proliferation between miR-410-3ptransfected cells and control cells increased with the incubation time (Fig. 2e).

\section{miR-410-3p-dependent regulation of cell cycle}

Due to the possibility of cell cycle regulation by miR-410$3 p$, we checked the expression of cyclin D1 and cyclin E1 that both drive G1/S phase transition as well as cyclin B1 that drives G2/M phase transition (Fig. 3). While no major changes in cyclins D1 and E1 were detected in studied cell lines, miR-410-3p mimic induced expression of cyclin B1 in AtT-20 cells (relative level 1.42, $p=0.001$ ) and suppressed in GH3 cells (relative level 0.95, $p=0.0259$ ). Moreover, we checked the expression of negative cell cycle regulators p14 (CDKN2A) and Wee1 on protein level (Fig. 4a). We found that miR-410-3p downregulated the level of p14 and Wee1 in RC-4B/C cells and the level of p14 in AtT-20 cells, but upregulated the level of both inhibitors of cell cycle in GH3 cells

\section{miR-410-3p regulates MAPK and PTEN/AKT pathways}

Constitutive activation of oncogenic kinases like AKT [23] or Erk1/2 [24] is often attributed a major role in promoting tumor invasion and proliferation. Since aberrant activation of MAPK and PTEN/AKT signaling pathways has been associated with pathogenesis of pituitary tumors [25-27] we decided to check whether miR-410-3p overexpression affected activation of these pathways differently in the tested cell lines. The results are shown in Fig. 4. We found that miR-410-3p upregulated the phospho-p44/42 MAPK (Erk1/2) (Thr202/Tyr204):total ERK1/2 ratio in all three cell lines, with the highest level in RC-4B/C cells $(3.78 \pm$ $0.05, p<0.001)$ and the lowest in GH3 cells $(1.43 \pm 0.24$, $p>0.05$ ). Moreover, we observed a significant downregulation of the level of total ERK1/2 in RC-4B/C cells $(0.38 \pm 0.09, p=0.0046$, unpaired $t$-test $)$ and a mild downregulation in the other two cell lines $(0.77 \pm 0.24$ in $\mathrm{GH} 3, p>0.05$, and $0.93 \pm 0.48$ in AtT-20, $p>0.05$, unpaired $t$-test). Further, we checked the level of PTEN as well as PTEN-dependent phospho-AKT T308 and mTORC2-dependent phospho-AKT S473. We found miR410-3p-dependent downregulation of PTEN in RC-4B/C $(0.58 \pm 0.07, p=0,0319)$ and AtT-20 cells $(0.70 \pm 0.14, p>$ 0.05 ) leading to a mild phosphorylation increase of AKT at T308 (relative level $1.85 \pm 0.49$ in RC-4B/C and $1.71 \pm 0.39$ in AtT-20 cells, $p>0.05$ ). The level of PTEN in GH3 cells was slightly upregulated $(1.38 \pm 0.22, p>0.05)$. In this setting, miR-410-3p caused a slight decrease in the T308 phosphorylation level of AKT $(0.86 \pm 0.05, p>0.05)$ in GH3. We also observed a upregulation of pAKT S473 in RC-4B/C and AtT-20 cells $(2.81 \pm 0.99$ and $1.80 \pm 0.55$, respectively, $p>0.05$ ) and downregulation in GH3 cells $(0.83 \pm 0.18, p>0.05)$. The level of pAKT T308/total AKT compared to pAKT S473/total AKT was higher in RC-4B/C cells while lower in AtT-20 cells.

\section{miR-410-3p-dependent regulation of STAT3}

miR-410-3p is also a known modulator of STAT3 (Signal Transducer and Activator of Transcription 3) activity [28]. We found upregulation in the phosphorylation of STAT3 

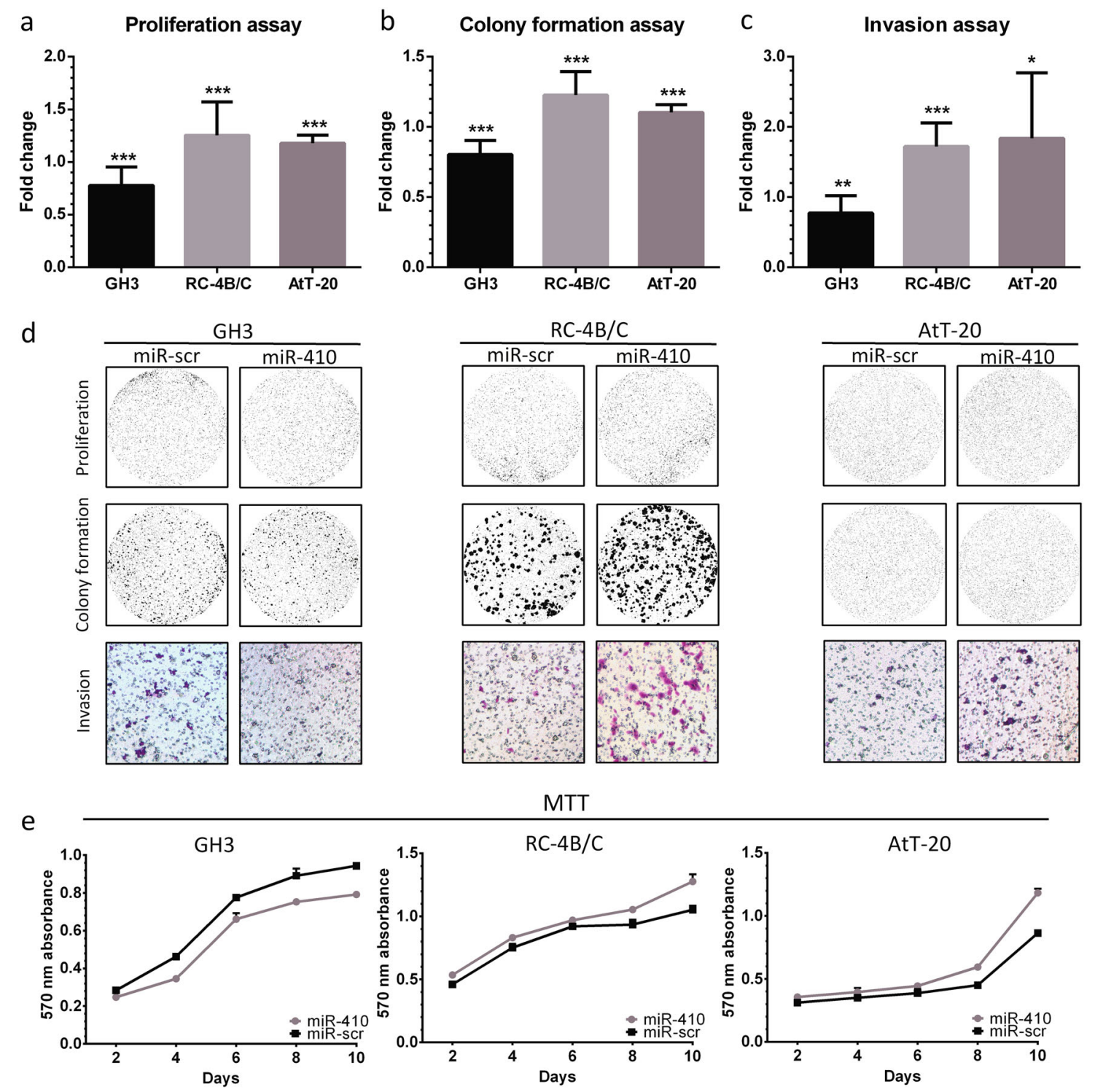

Fig. 2 miR-410-3p downregulates GH3 cells proliferation and invasiveness while it upregulates proliferation and invasiveness of RC-4B/ $\mathrm{C}$ and AtT-20 cells. The results of proliferation assay (a), colony formation assay (b), and invasion assay (c). Mean \pm SD. d Representative photos of proliferation, colony formation, and invasion assays. e The results of MTT. Mann-Whitney test $* p<0.05$, $* * p<0.01, * * * p<0.001$

molecular oncology is tissue- and context-dependent. miR410-3p may act as both oncomiR or tumor suppressor miR in different types of cancer [17]. It regulates crucial cellular processes including cell cycle, apoptosis, migration, and invasion. Müssnich et al. found that miR-410-3p is downregulated in gonadotroph adenomas compared with normal pituitary gland [29]. Moreover, they suggested that the downregulation of expression of miR-410-3p is specific to gonadotroph tumors because they noted upregulation of its expression in the majority of adenomas originating from mammosomatotroph cell lineage, i.e., somatotroph and lactotroph tumors. Further, they reported that miR-410-3p targets cyclin B1 and acts as a tumor suppressor miR. 


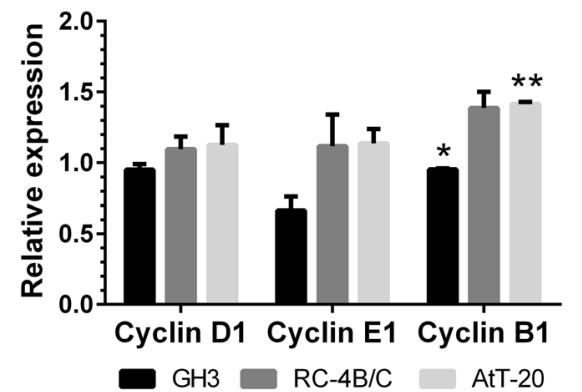

Fig. 3 The relative expression of cyclin D1, E1, and B1 on mRNA level in miR-410-3p-transfected cells, normalized to miR-scrambledtransfected cells. Mean \pm SD. Paired $t$-test $* p<0.05, * * p<0.01$
However, their conclusions were based on experiments performed only on HEK-293 cells, which does not reflect the unique biology of pituitary tumors. Similarly, Cheunsuchon et al. found downregulation of miR-410-3p expression in nonfunctioning pituitary adenomas, mainly gonadotroph tumors, and its upregulation in GH-, PRL-, and ACTH-secreting tumors [30]. We found that the expression of miR-410-3p was the highest in somatotroph pituitary adenomas, while it was lower in gonadotroph adenomas $(p<0.0001$, Dunn's multiple comparisons test). We found that the expression of miR-410-3p was higher in invasive compared to noninvasive tumors, however, it was not statistically significant due to a high heterogeneity in its
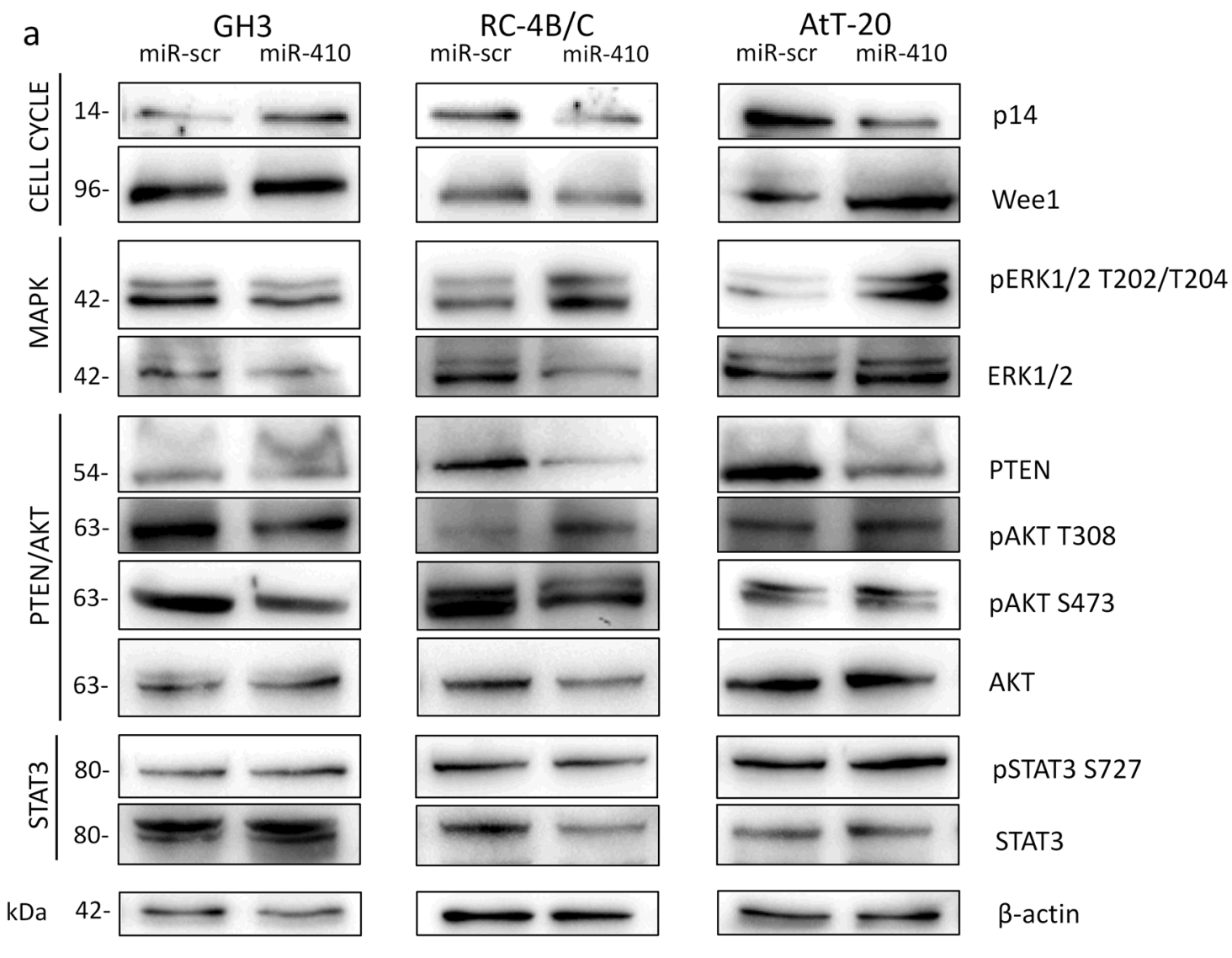

b

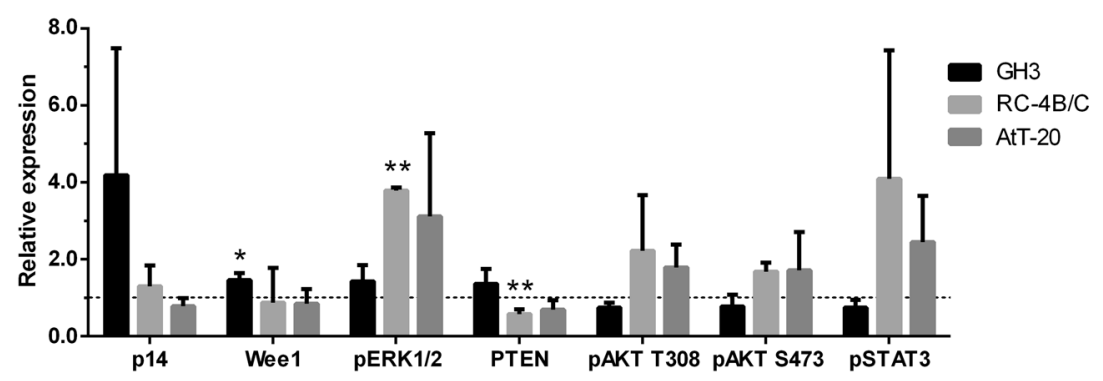

Fig. 4 miR-410-3p regulates cell cycle, MAPK, PTEN/AKT and STAT3 signaling pathways. a Representative western blots and $\beta$-actin as a loading control. b The results of densitometric analysis of relative p14 and Wee1 expression, pERK1/2:ERK1/2 total ratio, relative
PTEN expression, relative pAKT T308:AKT total ratio, pAKT S473: AKT total ratio, and relative pSTAT3:STAT3 total ratio. Normalized to miR-scrambled-transfected cells. Mean $\pm \mathrm{SD}$. Unpaired $t$-test $* p<$ $0.05, * * p<0.01, * * * p<0.001$ 
expression. Zhu et al. [22]. found that the expression of miR-410-3p was higher in bone-invasive pituitary adenoma compared to nonbone-invasive pituitary adenomas. The inconsistency between the expression of miR-410-3p in tissue samples and its role in vitro suggests a more complex role of miR-410-3p in pituitary adenomas in vivo, that has to be further investigated.

The results we present in this manuscript indicate that miR-410-3p plays different roles in adenomas originating from different lineages. It acts as oncomiR in $\mathrm{RC}-4 \mathrm{~B} / \mathrm{C}$ and AtT-20 cells and as tumor suppressor miR in GH3 pituitary adenoma cells. miR-410-3p upregulates pERK1/2 level and downregulates PTEN in RC-4B/C cells as well as upregulates cyclin B1 in AtT-20 cells. However, it upregulates Wee1 and downregulates cyclin B1 in GH3 cells.

Recently, it has been suggested that cyclins and cyclindependent kinases are crucial in the development and progression of pituitary adenomas [31-33]. The miRdependent regulation of cell cycle is important in the biology of pituitary adenoma [9]. Mitosis initiation is controlled by activation of a complex composed of cyclin B and CDK1 (cyclin-dependent kinase 1). In breast cancer and glioblastoma cells, miR-410-3p leads to growth inhibition through targeting CDK1 [34]. The expression of miR-410-3p may be induced by $\mathrm{p} 16^{\mathrm{INK} 4 \mathrm{a}}$, the inhibitor of G1-phase kinases, CDK4 and CDK6 [34]. In the pathogenesis of pituitary adenomas, the regulation of $\mathrm{G} 2 / \mathrm{M}$ phase transition and cyclin B1 caught particular attention. Its expression is higher in invasive compared to noninvasive pituitary adenomas [35]. We found that miR-410-3p mildly downregulated the expression of cyclin B1 in GH3 cells and upregulated in AtT-20 cells. We have also investigated the effect of miR410-3p on negative cell cycle regulators. The Wee1 kinase is a cell cycle inhibitor that interacts with CDK1 and induces $\mathrm{G} 2 / \mathrm{M}$ arrest. CDK1 is subject to inhibitory phosphorylation on Y15 catalyzed by Wee1 kinase [36]. Katayama et al. found that it is one of the signaling nodes through which AKT orchestrates cell cycle progression [37]. Wee1 can be phosphorylated by AKT at S642, which induces its nuclear-tocytoplasmic translocation and progression through the G2/M checkpoint. The expression of Weel is decreased in pituitary adenomas and is regulated by miRs $[9,38]$. We found that the expression of Wee1 was regulated in a miR-410-3pdependent manner. miR-410-3p upregulated the level of Wee1 as tumor suppressor miR in GH3 cells. We also observed mildly downregulation of Wee1 by miR-410-3p in $\mathrm{RC}-4 \mathrm{~B} / \mathrm{C}(0.88 \pm 0.52)$ and AtT-20 cells $(0.84 \pm 0.22)$.

MAPK and PTEN/AKT are the main signaling pathways responsible for the proliferation and invasiveness of cancer cells and play an essential role in tumor development and progression [25]. Their aberrant activation has been also described as an integral part of pituitary tumorigenesis
[25, 26]. Some authors describe synergistic interactions between both RAF/MEK/ERK1/2 and PI3K/AKT signaling pathways to maintain cell homeostasis and its disruption may lead to tumorigenesis [39, 40]. Both pathways are involved in the regulation of cyclin D1 and c-MYC expression. The inhibition of PI3K/AKT/mTOR seems to be a promising therapeutic tool for aggressive somatotroph tumors [41, 42] while ERK1/2 may be a useful therapeutic target to control GH secretion [43].

We found that miR-410-3p upregulated pERK1/2 in all three cell lines, especially in RC-4B/C and AtT-20. The downregulation of total ERK1/2 in cell lines may result from indirect regulation or by unconfirmed direct binding to $3^{\prime}$-UTR as ERK1/2 is a predictive target of miR-410-3p (TargetScan [44]). No data has been published so far concerning the possible mechanism of MAPK regulation by miR-410-3p and this finding warrants further investigation.

PTEN (phosphatase and tensin homologue) is one of the most important tumor suppressors [45]. It directly opposes the activity of PI3K by dephosphorylation of phosphatidylinositol-3,4,5-trisphosphate $\left(\mathrm{PIP}_{3}\right)$ leading to the suppression of PDK1/AKT pathway. PTEN inactivation is one of the most common alterations in human cancers [46]. miR410-3p targets and downregulates the expression of PTEN in prostate cancer leading to activation of AKT/mTOR pathways and promotion of cancer progression [47]. The expression of PTEN is downregulated in pituitary adenomas compared to normal pituitary tissues as well as in invasive adenomas compared to noninvasive [4, 48]. It was shown that miR-17-5p, miR-20a, miR-106b, and miR-200c target PTEN leading to the activation of AKT and increased cell proliferation and invasiveness [48-51]. We found that miR410-3p downregulated PTEN as well as it upregulated pAKT T308 and pAKT S473 in RC-4B/C and AtT-20 cells. However, miR-410-3p in GH3 cell line mildly upregulated PTEN which led to the downregulation of AKT phosphorylation. This could be one of the reasons for the observed differences in cell proliferation and invasion between these cell lines.

Next, we checked the effect of miR-410-3p on STAT3, a critical regulator of malignant transformation and tumor progression [52]. MicroRNAs are emerging as important regulators of STAT3 in the cancer pathogenesis [53]. In endothelial cells [54] and CD3 + T cells [28] miR-410-3p directly targets STAT3 and downregulates its expression. We found that miR-410-3p downregulated the level of STAT3 only in RC-4B/C cells (relative expression $0.37 \pm$ 0.19). However, miR-410-3p upregulated the net level of phospho-STAT3 in both RC-4B/C and AtT-20 cells, while it was downregulated in $\mathrm{GH} 3$ cells (Fig. 4). It may be due to the downregulation of SOCS3 (suppressors of 
cytokine signaling 3), an inhibitor of JAK kinase activity and STAT phosphorylation, by miR-410-3p [55]. Interestingly, the S727 phosphorylation site we studied is directly regulated by MAPK [56] and MTOR [57] kinases. Since the changes in S727 phosphorylation that we observe mirror the changes in pERK1/2, MAPK activity could be one of the factors contributing to the changes in STAT3 activity that we report. STAT3 is a transcription factor involved in cell proliferation, transformation, and invasion [58]. It was shown that STAT3 induced GH hypersecretion in somatotroph tumors [59]. However, there is no correlation between STAT3 expression and pituitary tumor invasiveness [60].

\section{Conclusions}

We have shown that miR-410-3p plays an opposite role as an oncomiR in gonadotroph $\mathrm{RC}-4 \mathrm{~B} / \mathrm{C}$ and corticotroph AtT-20 pituitary adenoma cells while as tumor suppressor miR in somatotroph GH3 pituitary adenoma cells. It regulates tumor cells proliferation and invasiveness through MAPK, PTEN/AKT, and STAT3 signaling pathways. We have shown that single miR may act differentially in different types of pituitary adenomas.

Funding This work was supported by a grant from the National Science Center, Poland UMO-2016/23/N/NZ5/02597 and the Medical University of Warsaw: 1M15/PM1/17.

\section{Compliance with ethical standards}

Conflict of interest The authors declare that they have conflict of interest.

Publisher's note: Springer Nature remains neutral with regard to jurisdictional claims in published maps and institutional affiliations.

Open Access This article is distributed under the terms of the Creative Commons Attribution 4.0 International License (http://crea tivecommons.org/licenses/by/4.0/), which permits unrestricted use, distribution, and reproduction in any medium, provided you give appropriate credit to the original author(s) and the source, provide a link to the Creative Commons license, and indicate if changes were made.

\section{References}

1. S.L. Asa, S. Ezzat, The pathogenesis of pituitary tumours. Nat. Rev. Cancer 2(11), 836-849 (2002). https://doi.org/10.1038/ nrc926

2. M.V. Iorio, C.M. Croce, MicroRNA dysregulation in cancer: diagnostics, monitoring and therapeutics. A comprehensive review. EMBO Mol. Med. 4(3), 143-159 (2012). https://doi.org/ 10.1002/emmm.201100209

3. W. He, L. Huang, M. Li, Y. Yang, Z. Chen, X. Shen, MiR-148b, MiR-152/ALCAM axis regulates the proliferation and invasion of pituitary adenomas cells. Cell. Physiol. Biochem.: Int. J. Exp. Cell. Physiol., Biochem., Pharmacol. 44(2), 792-803 (2017). https://doi.org/10.1159/000485342

4. Z. Zheng, Y. Zhang, Z. Zhang, Y. Yang, T. Song, Effect of miR$106 \mathrm{~b}$ on invasiveness of pituitary adenoma via PTEN-PI3K/AKT. Med. Sci. Monit.: Int. Med. J. Exp. Clin. Res. 23, 1277-1285 (2017)

5. Y. Peng, C.M. Croce, The role of MicroRNAs in human cancer. Signal Transduct. Target Ther. 1, 15004 (2016). https://doi.org/10. 1038/sigtrans.2015.4

6. A.A. Svoronos, D.M. Engelman, F.J. Slack, OncomiR or tumor suppressor? The duplicity of microRNAs in cancer. Cancer Res. 76(13), 3666-3670 (2016). https://doi.org/10.1158/0008-5472.Ca n-16-0359

7. X.H. Li, E.L. Wang, H.M. Zhou, K. Yoshimoto, Z.R. Qian, MicroRNAs in Human Pituitary Adenomas. Int. J. Endocrinol. 2014, 435171 (2014). https://doi.org/10.1155/2014/435171

8. M. Sapochnik, L.E. Nieto, M. Fuertes, E. Arzt, Molecular mechanisms underlying pituitary pathogenesis. Biochem. Genet. 54(2), 107-119 (2016). https://doi.org/10.1007/s10528-015-9709-6

9. T. Zhang, Z. Yang, H. Gao, Advancements in the study of miRNA regulation during the cell cycle in human pituitary adenomas. J. Neurooncol. 134(2), 253-258 (2017). https://doi.org/10.1007/ s11060-017-2518-5

10. Y.J. Lee, J.M. Cho, J.H. Moon, C.R. Ku, J. Kim, S.H. Kim, E.J. Lee, Increased miR-338-3p expression correlates with invasiveness of GH-producing pituitary adenomas. Endocrine 58(1), 184-189 (2017). https://doi.org/10.1007/s12020-017-1390-6

11. G. Stilling, Z. Sun, S. Zhang, L. Jin, A. Righi, G. Kovacs, M. Korbonits, B.W. Scheithauer, K. Kovacs, R.V. Lloyd, MicroRNA expression in ACTH-producing pituitary tumors: up-regulation of microRNA-122 and -493 in pituitary carcinomas. Endocrine 38(1), 67-75 (2010). https://doi.org/10.1007/s12020-010-9346-0

12. F. Garbicz, D. Mehlich, B. Rak, E. Sajjad, M. Maksymowicz, W. Paskal, G. Zielinski, P.K. Wlodarski, Increased expression of the microRNA 106b 25 cluster and its host gene MCM7 in corticotroph pituitary adenomas is associated with tumor invasion and Crooke's cell morphology. Pituitary 20(4), 450-463 (2017). https://doi.org/10.1007/s11102-017-0805-y

13. E. Gentilin, E. Degli Uberti, M.C. Zatelli, Strategies to use microRNAs as therapeutic targets. Best practice \& research. Clin. Endocrinol. Metab. 30(5), 629-639 (2016). https://doi.org/10. 1016/j.beem.2016.10.002

14. A. Bottoni, M.C. Zatelli, M. Ferracin, F. Tagliati, D. Piccin, C. Vignali, G.A. Calin, M. Negrini, C.M. Croce, E.C. Degli Uberti, Identification of differentially expressed microRNAs by microarray: a possible role for microRNA genes in pituitary adenomas. J. Cell. Physiol. 210(2), 370-377 (2007). https://doi.org/10.1002/ jcp. 20832

15. B. Rak, D. Mehlich, F. Garbicz, Z. Domosud, W. Paskal, J.M. Marczewska, P.K. Wlodarski, Post-transcriptional regulation of MMP16 and TIMP2 expression via miR-382, miR-410 and miR$200 \mathrm{~b}$ in endometrial cancer. Cancer Genom. Proteom. 14(5), 389-401 (2017). https://doi.org/10.21873/cgp.20049

16. B. Rak, F. Garbicz, W. Paskal, K. Pelka, J.M. Marczewska, D. Wolosz, P. Wlodarski, The expression of MMP-14 and microRNA-410 in FFPE tissues of human endometrial adenocarcinoma. Histol. Histopathol. 31(8), 911-920 (2016). https://doi. org/10.14670/hh-11-728

17. Wen, R., Umeano, A. C., Essegian, D. J., Sabitaliyevich, U. Y., Wang, K., Farooqi, A. A, Role of microRNA-410 in molecular oncology: a double edged sword. J. Cell Biochem. (2018). https:// doi.org/10.1002/jcb.27251

18. K.J. Livak, T.D. Schmittgen, Analysis of relative gene expression data using real-time quantitative PCR and the 2(-Delta Delta C(T)) 
Method. Methods (San. Diego, Calif.) 25(4), 402-408 (2001). https://doi.org/10.1006/meth.2001.1262

19. C.L. Andersen, J.L. Jensen, T.F. Ørntoft, Normalization of realtime quantitative reverse transcription-PCR data: a model-based variance estimation approach to identify genes suited for normalization, applied to bladder and colon cancer data sets. Cancer Res. 64(15), 5245 (2004). https://doi.org/10.1158/0008-5472. CAN-04-0496

20. J. Polkowska, A. Bérault, I. Hurbain-Kosmath, G. Jolly, M. Jutisz, Bihormonal cells producing gonadotropins and prolactin in a rat pituitary tumor cell line (RC-4B/C). Neuroendocrinology 54(3), 267-273 (1991). https://doi.org/10.1159/000125885

21. C. Guzmán, M. Bagga, A. Kaur, J. Westermarck, D. Abankwa, ColonyArea: an ImageJ plugin to automatically quantify colony formation in clonogenic assays. PLoS ONE 9(3), e92444 (2014). https://doi.org/10.1371/journal.pone.0092444

22. Zhu, H., Guo, J., Shen, Y., Dong, W., Gao, H., Miao, Y., Li, C., Zhang, Y, Functions and mechanisms of tumor necrosis factoralpha and noncoding RNAs in bone-invasive pituitary adenomas. Clin. Cancer Res. (2018) https://doi.org/10.1158/1078-0432.Ccr18-0472

23. L. Larue, A. Bellacosa, Epithelial-mesenchymal transition in development and cancer: role of phosphatidylinositol $3^{\prime}$ kinase/ AKT pathways. Oncogene 24, 7443 (2005). https://doi.org/10. 1038/sj.onc.1209091

24. M. Navandar, A. Garding, S.K. Sahu, A. Pataskar, S. Schick, V.K. Tiwari, ERK signalling modulates epigenome to drive epithelial to mesenchymal transition. Oncotarget 8(17), 29269-29281 (2017). https://doi.org/10.18632/oncotarget.16493

25. D. Dworakowska, E. Wlodek, C.A. Leontiou, S. Igreja, M. Cakir, M. Teng, N. Prodromou, M.I. Goth, S. Grozinsky-Glasberg, M. Gueorguiev, B. Kola, M. Korbonits, A.B. Grossman, Activation of RAF/MEK/ERK and PI3K/AKT/mTOR pathways in pituitary adenomas and their effects on downstream effectors. Endocr. Relat. Cancer 16(4), 1329-1338 (2009). https://doi.org/10.1677/ erc-09-0101

26. H. Rubinfeld, I. Shimon, PI3K/Akt/mTOR and Raf/MEK/ERK signaling pathways perturbations in non-functioning pituitary adenomas. Endocrine 42(2), 285-291 (2012). https://doi.org/10. 1007/s12020-012-9682-3

27. H.L. Robbins, A. Hague, The PI3K/Akt pathway in tumors of endocrine tissues. Front. Endocrinol. 6, 188 (2015). https://doi. org/10.3389/fendo.2015.00188

28. D. Liu, N. Zhang, X. Zhang, M. Qin, Y. Dong, L. Jin, MiR-410 down-regulates the expression of interleukin-10 by targeting STAT3 in the pathogenesis of systemic lupus erythematosus. Cell. Physiol. Biochem.: Int. J. Exp. Cell. Physiol., Biochem., Pharmacol. 39(1), 303-315 (2016). https://doi.org/10.1159/000445625

29. P. Mussnich, G. Raverot, M.L. Jaffrain-Rea, F. Fraggetta, A. Wierinckx, J. Trouillas, A. Fusco, D. D'Angelo, Downregulation of miR-410 targeting the cyclin B1 gene plays a role in pituitary gonadotroph tumors. Cell cycle (Georget., Tex.) 14(16), 2590-2597 (2015). https://doi.org/10.1080/15384101.2015.1064207

30. P. Cheunsuchon, Y. Zhou, X. Zhang, H. Lee, W. Chen, Y. Nakayama, K.A. Rice, E. Tessa Hedley-Whyte, B. Swearingen, A. Klibanski, Silencing of the imprinted DLK1-MEG3 Locus in human clinically nonfunctioning pituitary adenomas. Am. J. Pathol. 179(4), 2120-2130 (2011). https://doi.org/10.1016/j.ajpa th.2011.07.002

31. Z. Hou, J. Yang, G. Wang, C. Wang, H. Zhang, Bioinformatic analysis of gene expression profiles of pituitary gonadotroph adenomas. Oncol. Lett. 15(2), 1655-1663 (2018). https://doi.org/ 10.3892/ol.2017.7505

32. S. Melmed, Pathogenesis of pituitary tumors. Nat. Rev. Endocrinol. 7(5), 257-266 (2011). https://doi.org/10.1038/nrendo.2011.40
33. J. S. Lim, M. K. Lee, E. Choi, N. Hong, Il S. Jee, S. H. Kim, E. J. Lee, Hormonal aggressiveness according to the expression of cellular markers in corticotroph adenomas. Endocrine (2018). https://doi.org/10.1007/s12020-018-1815-x

34. W.W. Chien, C. Domenech, R. Catallo, T. Kaddar, J.P. Magaud, G. Salles, M. Ffrench, Cyclin-dependent kinase 1 expression is inhibited by p16(INK4a) at the post-transcriptional level through the microRNA pathway. Oncogene 30(16), 1880-1891 (2011). https://doi.org/10.1038/onc. 2010.570

35. G. Raverot, A. Wierinckx, E. Dantony, C. Auger, G. Chapas, L. Villeneuve, T. Brue, D. Figarella-Branger, P. Roy, E. Jouanneau, M. Jan, J. Lachuer, J. Trouillas, Prognostic factors in prolactin pituitary tumors: clinical, histological, and molecular data from a series of 94 patients with a long postoperative follow-up. J. Clin. Endocrinol. Metab. 95(4), 1708-1716 (2010). https://doi.org/10. 1210/jc.2009-1191

36. N. Watanabe, M. Broome, T. Hunter, Regulation of the human WEE1Hu CDK tyrosine 15-kinase during the cell cycle. EMBO J. 14(9), 1878-1891 (1995)

37. K. Katayama, N. Fujita, T. Tsuruo, Akt/Protein kinase B-dependent phosphorylation and inactivation of WEE1Hu promote cell cycle progression at $\mathrm{G}_{2} / \mathrm{M}$ Transition. Mol. Cell. Biol. 25(13), 5725 (2005)

38. H. Butz, I. Liko, S. Czirjak, P. Igaz, M.M. Khan, V. Zivkovic, K. Balint, M. Korbonits, K. Racz, A. Patocs, Down-regulation of Wee1 kinase by a specific subset of microRNA in human sporadic pituitary adenomas. J. Clin. Endocrinol. Metab. 95(10), E181-E191 (2010). https://doi.org/10.1210/jc.2010-0581

39. A.K. Roof, A. Gutierrez-Hartmann, Consider the context: Ras/ ERK and PI3K/AKT/mTOR signaling outcomes are pituitary cell type-specific. Mol. Cell. Endocrinol. 463, 87-96 (2018). https:// doi.org/10.1016/j.mce.2017.04.019

40. Z. Suojun, W. Feng, G. Dongsheng, L. Ting, Targeting Raf/MEK/ ERK pathway in pituitary adenomas. Eur. J. cancer (Oxf., Engl.: 1990) 48(3), 389-395 (2012). https://doi.org/10.1016/j.ejca.2011. 11.002

41. Pivonello, C., Patalano, R., Solari, D., Auriemma, R. S., Frio, F., Vitulli, F., Grasso, L. F. S., Di Cera, M., De Martino, M. C., Cavallo, L. M., Cappabianca, P., Colao, A., Pivonello, R, Effect of combined treatment with a pan-PI3K inhibitor or an isoformspecific $\mathrm{PI} 3 \mathrm{~K}$ inhibitor and everolimus on cell proliferation in $\mathrm{GH}-$ secreting pituitary tumour in an experimental setting. Endocrine (2018). https://doi.org/10.1007/s12020-018-1677-2

42. E.A. Sajjad, G. Zielinski, M. Maksymowicz, L. Hutnik, T. Bednarczuk, P. Wlodarski, mTOR is frequently active in GHsecreting pituitary adenomas without influencing their morphopathological features. Endocr. Pathol. 24(1), 11-19 (2013). https:// doi.org/10.1007/s12022-012-9230-y

43. C. Di Pasquale, E. Gentilin, S. Falletta, M. Bellio, M. Buratto, E. Degli Uberti, M. Chiara Zatelli, PI3K/Akt/mTOR pathway involvement in regulating growth hormone secretion in a rat pituitary adenoma cell line. Endocrine 60(2), 308-316 (2018). https://doi.org/10.1007/s12020-017-1432-0

44. V. Agarwal, G.W. Bell, J.-W. Nam, D.P. Bartel, Predicting effective microRNA target sites in mammalian mRNAs. eLife 4, e05005 (2015). https://doi.org/10.7554/eLife.05005

45. M.S. Song, L. Salmena, P.P. Pandolfi, The functions and regulation of the PTEN tumour suppressor. Nat. Rev. Mol. Cell Biol. 13, 283 (2012). https://doi.org/10.1038/nrm3330. https://www. nature.com/articles/nrm3330\#supplementary-information

46. N. Chalhoub, S.J. Baker, PTEN and the PI3-Kinase Pathway in Cancer. Annu. Rev. Pathol. 4, 127-150 (2009). https://doi.org/10. 1146/annurev.pathol.4.110807.092311

47. Zhang, Y., Zhang, D., Lv, J., Wang, S., Zhang, Q, miR-410-3p promotes prostate cancer progression via regulating PTEN/AKT/ 
mTOR signaling pathway. Biochem Biophys. Res. Commun. (2018). https://doi.org/10.1016/j.bbrc.2018.06.176

48. K. Zhou, T. Zhang, Y. Fan, Du.G. Serick, P. Wu, D. Geng, MicroRNA-106b promotes pituitary tumor cell proliferation and invasion through PI3K/AKT signaling pathway by targeting PTEN. Tumour Biol.: J. Int. Soc. Oncodev. Biol. Med. 37(10), 13469-13477 (2016). https://doi.org/10.1007/s13277-016$5155-2$

49. Z. Wei, C. Zhou, M. Liu, Y. Yao, J. Sun, J. Xiao, W. Ma, H. Zhu, R. Wang, MicroRNA involvement in a metastatic non-functioning pituitary carcinoma. Pituitary 18(5), 710-721 (2015). https://doi. org/10.1007/s11102-015-0648-3

50. C. Liao, W. Chen, X. Fan, X. Jiang, L. Qiu, C. Chen, Y. Zhu, H. Wang, MicroRNA-200c inhibits apoptosis in pituitary adenoma cells by targeting the PTEN/Akt signaling pathway. Oncol. Res. 21(3), 129-136 (2013). https://doi.org/10.3727/ $096504013 \times 13832473329999$

51. A. Wierinckx, M. Roche, C. Legras-Lachuer, J. Trouillas, G. Raverot, J. Lachuer, MicroRNAs in pituitary tumors. Mol. Cell. Endocrinol. 456, 51-61 (2017). https://doi.org/10.1016/j.mce. 2017.01.021

52. K. Al Zaid Siddiquee, J. Turkson, STAT3 as a target for inducing apoptosis in solid and hematological tumors. Cell Res. 18, 254 (2008). https://doi.org/10.1038/cr.2008.18

53. H. Yu, H. Lee, A. Herrmann, R. Buettner, R. Jove, Revisiting STAT3 signalling in cancer: new and unexpected biological functions. Nat. Rev. Cancer 14, 736 (2014). https://doi.org/10. 1038/nrc3818

54. M.Y. Hu, X.B. Du, H.B. Hu, Y. Shi, G. Chen, Y.Y. Wang, MiR410 inhibition induces HUVECs proliferation and represses oxLDL-triggered apoptosis through activating STAT3. Biomed.
Pharmacother. $=$ Biomedecine $\quad$ Pharmacother. 101， 585-590 (2018). https://doi.org/10.1016/j.biopha.2018.02.111

55. M. Li, R. Zheng, F.L. Yuan, MiR-410 affects the proliferation and apoptosis of lung cancer A549 cells through regulation of SOCS3/ JAK-STAT signaling pathway. Eur. Rev. Med. Pharmacol. Sci. 22(18), 5987-5993 (2018). https://doi.org/10.26355/eurrev_ 201809_15933

56. J. Chung, E. Uchida, T.C. Grammer, J. Blenis, STAT3 serine phosphorylation by ERK-dependent and -independent pathways negatively modulates its tyrosine phosphorylation. Mol. Cell. Biol. 17(11), 6508-6516 (1997)

57. K. Yokogami, S. Wakisaka, J. Avruch, S.A. Reeves, Serine phosphorylation and maximal activation of STAT3 during CNTF signaling is mediated by the rapamycin target mTOR. Curr. Biol.: CB 10(1), 47-50 (2000)

58. M. Trovato, M.L. Torre, M. Ragonese, A. Simone, R. Scarfi, V. Barresi, G. Giuffre, S. Benvenga, F.F. Angileri, G. Tuccari, F. Trimarchi, R.M. Ruggeri, S. Cannavo, HGF/c-met system targeting PI3K/AKT and STAT3/phosphorylated-STAT3 pathways in pituitary adenomas: an immunohistochemical characterization in view of targeted therapies. Endocrine 44(3), 735-743 (2013). https://doi.org/10.1007/s12020-013-9950-x

59. C. Zhou, Y. Jiao, R. Wang, S.G. Ren, K. Wawrowsky, S. Melmed, STAT3 upregulation in pituitary somatotroph adenomas induces growth hormone hypersecretion. J. Clin. Invest. 125(4), 1692-1702 (2015). https://doi.org/10.1172/jci78173

60. I. Valiulyte, G. Steponaitis, D. Skiriute, A. Tamasauskas, P. Vaitkiene, Signal transducer and activator of transcription 3 (STAT3) promoter methylation and expression in pituitary adenoma. Bmc. Med. Genet. 18(1), 72 (2017). https://doi.org/10. 1186/s12881-017-0434-3

\section{Affiliations}

\section{Tomasz M. Grzywa $\mathbb{1}^{1,2} \cdot$ Klaudia Klicka $\mathbb{D}^{1,2} \cdot$ Beata Rak $\mathbb{1}^{1,2,3,4} \cdot$ Dawid Mehlich ${ }^{1,2,5} \cdot$ Filip Garbicz $\mathbb{D}^{1,2,3,6}$. Grzegorz Zieliński $^{7} \cdot$ Maria Maksymowicz $^{8} \cdot$ Emir Sajjad $^{2,7} \cdot$ Paweł K. Włodarski $\mathbb{1}^{1,2}$}

1 Center for Preclinical Research, The Department of Methodology, Medical University of Warsaw, 1B Banacha Str., 02-097 Warsaw, Poland

2 Center for Preclinical Research, The Department of Histology and Embryology, Medical University of Warsaw, 1B Banacha Str., 02097 Warsaw, Poland

3 Postgraduate School of Molecular Medicine, Warsaw, Poland

4 The Department of Internal Diseases and Endocrinology, Public Central Teaching Hospital, Medical University of Warsaw, 1A Banacha Str., 02-097 Warsaw, Poland

5 Laboratory of Experimental Medicine, Centre of New
Technologies, University of Warsaw, 2C Banacha Str., 02-097 Warsaw, Poland

6 Department of Experimental Hematology, Institute of Hematology and Transfusion Medicine, 14 Indiry Gandhi Str., 02-776 Warsaw, Poland

7 The Department of Neurosurgery, Military Institute of Medicine, 128 Szaserów Str., 04-141 Warsaw, Poland

8 The Department of Pathology and Laboratory Diagnostics, M. Skłodowska-Curie Memorial Cancer Centre and Institute of Oncology, 5 Roentgena Str., 02-781 Warsaw, Poland 